\title{
ISOLATED OCULOMOTOR NERVE PALSY
}

\author{
Melissa T. E. Ratag \\ Ralf R. Pangalila \\ Bagian Ilmu Kesehatan Mata Fakultas Kedokteran \\ Universitas Sam Ratulangi Manado \\ Email: mratag18@yahoo.co.id
}

\begin{abstract}
We reported a case of a 59-year-old male who came to the hospital with the chief complaint of a droopy upper right eyelid originating a month before, accompanied by diplopia. This patient was also suffering from uncontrolled hypertension. The ophthalmologic examination of the right eye showed a best corrected visual acuity (BCVA) of 1.0. In the primary position there was a deviation to the temporal side; limitations on elevation, adduction, and depression; and an endorotation on nasal down gaze. The aberrant regenerative trigeminal nerve was noticed, but the relative afferent pupillary defect (RAPD) was not found. The anterior and posterior segments of the right eye were normal. Laboratory tests were within normal limits and the CT-scan did not show any abnormality. Conclusion: Based on all the tests performed, the diagnosis of the patient was an isolated oculomotor nerve palsy of the right eye. The patient was treated with a non-steroid anti inflammatory drug and a neurotropic vitamine, and had to be observed for three months.
\end{abstract}

Keywords: palsy, oculomotor nerve, right eye

\begin{abstract}
Abstrak: Kami melaporkan kasus seorang laki-laki berusia 59 tahun dengan keluhan utama kelopak mata atas kanan tertutup sejak satu bulan lalu, disertai diplopia. Dalam anamnesis ditemukan adanya riwayat hipertensi sedangkan riwayat trauma tidak ada. Pemeriksaan oftalmologi mata kanan didapatkan tajam penglihatan $6 / 6$, pergerakan bola mata kanan tampak sedikit deviasi ke temporal pada posisi primer, serta keterbatasan dalam elevasi, aduksi, dan depresi. Mata kanan tampak endorotasi saat melirik ke nasal bawah dan terdapat aberrant regenerative; relative afferent pupillary defect (RAPD) tidak ditemukan. Segmen anterior dan posterior dalam batas normal. Pemeriksaan laboratorium dan CT scan kepala dalam batas normal. Simpulan: Berdasarkan hasil pemeriksaan oftalmologik dan pemeriksaan penunjang ditegakkan diagnosis isolated oculomotor nerve palsy mata kanan yang ditangani dengan pemberian anti inflamasi non steroid dan neurotropik per oral sambil diobservasi selama tiga bulan.
\end{abstract}

Kata kunci: kelumpuhan, saraf okulomotor, mata kanan

Penyebab kematian yang paling sering pada suatu kelumpuhan saraf okulomotor yaitu perdarahan subaraknoid saat terjadinya robekan anerisma dari arteri komunikans posterior, gangguan infiltratif meningitis atau meningeal dan neoplastik. ${ }^{1,2}$ Penelitian dari Rowe ${ }^{3}$ mengemukakan mengenai kejadian kelumpuhan saraf motorik kranialis setelah stroke pada 498 pasien; 23 di antaranya (26\%) mengalami kelumpuhan saraf okulomotor unilateral.3

Penyebab dari kelumpuhan saraf okulomotor sering menjadi tantangan bagi para dokter ahli penyakit mata, dokter ahli penyakit saraf, dan dokter ahli bedah saraf. Penyebab kelumpuhan saraf okulomotor dapat bersifat jinak, tetapi di sisi lain terdapat penyebab yang dapat mengancam nyawa, terutama aneurisma. Robeknya aneurisma serebral dapat membawa risiko 
kematian sampai $50 \%$. Lokalisasi neuroanatomi dan penentuan penyebab lesi merupakan kunci keberhasilan penanganan kelumpuhan saraf okulomotor. ${ }^{3}$

Kelumpuhan saraf okulomotor terisolasi sering terletak pada ruang subaraknoid yang diakibatkan oleh iskemia, aneurisma, trauma, migrain, tumor, dan anomali kongenital. ${ }^{4,5}$ Ada tidaknya keterlibatan pupil dapat membantu mengarahkan penanganan yang akan dilakukan, bedah atau non-bedah. Kelumpuhan saraf okulomotor akut memerlukan pemeriksaan pencitraan saraf (neuroimaging) untuk menyingkirkan kemungkinan aneurisma. ${ }^{6}$

\section{LAPORAN KASUS}

Kami melaporkan kasus seorang lakilaki berusia 59 tahun, suku Sangir dengan keluhan kelopak mata kanan atas tertutup. Keluhan ini sudah dialami sejak satu bulan lalu, diawali dengan penglihatan ganda yang berangsur-angsur hilang saat kelopak mata semakin tertutup. Pasien tidak mengeluh nyeri kepala, nyeri di sekitar kelopak mata, atau nyeri saat menggerakkan bola mata. Riwayat darah tinggi diketahui sejak saat serangan mata tertutup, yakni dua bulan yang lalu. Riwayat diabetes, penyakit sistemik lainnya, serta riwayat trauma kepala dan mata disangkal. Dalam keluarga hanya pasien ini yang menderita penyakit demikian.

Pemeriksaan fisik umum ditemukan tekanan darah 110/80 mm $\mathrm{Hg}$, nadi 80x/ menit, respirasi $20 \mathrm{x} /$ menit, dan suhu badan 36,7 C.

Pemeriksaan oftalmologik mata kanan yang ditemukan yaitu: tajam penglihatan 6/6; tekanan bola mata $12,2 \mathrm{~mm} \mathrm{Hg}$; pada pemeriksaan pergerakan bola mata, tampak sedikit deviasi ke temporal pada posisi primer, serta keterbatasan dalam elevasi, aduksi, dan depresi; mata tampak endorotasi saat melirik ke arah nasal bawah; dan saat mata kanan melirik ke bawah, tampak kelopak mata atas kanan terbuka yang menandakan adanya aberrant regenerative saraf okulomotor. Diameter pupil sama besar untuk kedua mata, dengan refleks pupil normal dan tidak ditemukan relative afferent pupillary defect (RAPD). Pada pemeriksaan segmen anterior kedua mata dengan slit lamp biomikroskopi kornea, lensa dan vitreus jernih, dan iris normal. Pada pemeriksaan oftalmoskopi direct dan indirect, papil, makula, dan retina tampak normal.

Pemeriksaan laboratorium darah dalam batas normal. Pemeriksaan pencitraan $(C T$ Scan) kepala dengan kontras tidak ditemukan massa atau aneurisma.

Pasien didiagnosis sebagai paresis nervus okulomotor terisolasi disertai sparing pupil mata kanan. Penatalaksanaan secara medik dengan pemberian terapi anti inflamasi non-steroid (AINS) dan neurotropik per oral, dan diobservasi selama tiga bulan. Selama observasi, dilakukan pemantauan pupil sparing dan perkembangan aberrant regenerative.

\section{BAHASAN}

Saraf kranial okulomotor (saraf kranial III) memasok eferen motorik ke otot levator palpebra superior dan empat otot ekstra-okular (rektus medial, rektus superior, rektus inferior, dan oblik inferior). Saraf ini juga membawa impuls parasimpatis presinaptik ke otot sfingter pupil dan iris. Pasien dengan paresis saraf okulomotor akan memberikan tanda-tanda seperti palpebra superior ptosis, penglihatan ganda, mata berabduksi pada posisi primer, abduksi normal, keterbatasan dalam aduksi, keterbatasan dalam depresi dan elevasi, intorsi pada saat melirik ke bawah dan pupil mid-dilatasi. ${ }^{7}$

Pada pasien ini ditemukan ptosis unilateral pada mata kanan dan tanda-tanda lainnya seperti yang sudah dijelaskan semula, ${ }^{7}$ tetapi pupil tidak mengalami dilatasi (pupil sparing). Keterlibatan saraf kranial lainnya seperti saraf troklearis dan abdusen tidak ditemukan, sehingga dapat dikatakan bahwa pasien ini mengalami kelumpuhan saraf okulomotor terisolasi. ${ }^{8}$ Kelumpuhan terjadi secara spontan tanpa didahului oleh trauma atau nyeri kepala yang hebat. Selain tanda-tanda tersebut, terdapat juga tanda 
regenerasi aberan, yaitu saat penderita disarankan untuk menutup kelopak mata kanan dengan rapat, kelopak tersebut justru tampak membuka. Meskipun hal ini tidak melibatkan pupil, dibutuhkan observasi yang teliti mengenai perkembangan pupil.

Pemeriksaan pencitraan kepala dengan kontras harus tetap dilakukan mengingat terdapat tanda regenerasi aberan meskipun hasilnya tidak memperlihatkan adanya massa, aneurisma, dan penyebab lain. Pemeriksaan serum darah yang normal untuk kadar gula dan profil lipid menyingkirkan kemungkinan vaskulopati, namun meski demikian perlu pengawasan lanjut.

Penyebab yang paling mungkin dari kelumpuhan saraf III ini ialah neuropati kranial iskemik berdasarkan adanya riwayat hipertensi, usia 59 tahun, pupil sparing, dan tidak disertai nyeri kepala meskipun profil lipid dan gula darahnya normal. ${ }^{3}$ Pemeriksaan penunjang lainnya seperti Magnetic Resonance Angiography MRA) atau Computed Tomography Angiography (CTA) perlu dilakukan untuk membuktikan hal ini. ${ }^{6}$

Pasien ini ditangani secara non-bedah dengan pemberian neurotropik dan AINS, sambil tetap dievaluasi fungsi neurologik dan diharapkan pasien dapat mengalami pemulihan paresis dalam tiga bulan. Hal ini dapat dievaluasi secara klinis melalui keadaan pupil yang pada saat observasi hari ke-5 dan setiap 4-6 minggu dalam kurun tersebut, pupil tidak mengalami dilatasi. ${ }^{9}$ Jika tetap tidak terjadi perubahan paresis atau pupil mengalami dilatasi setelah kurun waktu tersebut, kemungkinan pupil akan berdilatasi akibat perkembangan neurologik yang abnormal dan progresifitas paresis saraf okulomotor. Pemeriksaa MRI/MRA harus segera dilakukan, dan selanjutnya pasien dirujuk ke dokter ahli penyakit dalam untuk penanganan faktor-faktor risiko penyakit vaskulopati. ${ }^{10}$

\section{SIMPULAN}

Kelumpuhan saraf okulomotor terisolasi merupakan keadaan yang sangat serius di bidang oftalmologi dan memerlukan pemeriksaan dan penanganan yang segera dan teliti.

Berdasarkan hasil pemeriksaan klinis dan pencitraan kepala, pasien didiagnosis sebagai isolated oculomotor nerve pasly pada mata kanan. Prognosis pasien ini cukup baik karena tidak didapatkan suatu aneurisma atau massa tumor.

\section{DAFTAR PUSTAKA}

1. Zorab RA, Dondrea CL, Arturo C. Third nerve palsy. Neuro-ophthalmology in American Academy of Ophthalmology. The Foundation of American Academy of Ophthalmology. 2010;5:228-32.

2. Ehlers JP, Shah CP. Isolated third nerve palsy. In: Ehlers JP, Shah CP, editors. The Wills Eye Manual (Fifth Edition). Philadelphia: Lippincott William \& Wilkins, 2008; p. 231-4.

3. Rowe S. Prevalence of ocular motor cranial nerve palsy and associations following stroke. Scientific Journal of the Royal College of Ophthalmology. Eye. 2011;25:881-7.

4. Jacobson DM. McCanna TD, Layde PM. Risk factor for ischemic ocular motor nerve palsies. Arch Ophthalmology. 1994;112:961.

5. Jacobson DM. Relative pupil-sparing third nerve palsy: etiology and clinical variables predictive of mass. Neurology. 2001;56:797.

6. Blake PY, Mark AS, Kattah J, Kolsky M. Magnetic resonance of oculomotor nerve palsy. AJNR Am J Neuroradiol.1995;16(9):1665-72.

7. Kansky J. Third Nerve. In: Edwards R, editor. Clinical Ophthalmology A Synopis (Second edition). Philadelphia: Butterworth-Heinemann Elsevier, 2009; p. 422-4.

8. Nadeau SE, Trobe JD. Pupil sparing in oculomotor palsy: a brief review. Ann Neurol San Fransisco. 1983;13:143.

9. Trobe JD. Managing oculomotor nerve palsy. JAMA Ophthalmol. 1998; 116(6):798.

10. Keane JR. Third nerve palsy: analysis of 1400 personally-examined in patients. Canadian Journal Neurology. 2010; 37(5):662-70. 